\title{
What's New in Pathology Newsletter by PathologyOutlines.com
}

\author{
Nat Pernick \\ PathologyOutlines.com, Inc., Bingham Farms, MI, USA
}

PathologyOutlines.com is pleased to collaborate with JPTM to publish its What's New in Pathology newsletter, written by our Editorial Board to provide updated subspecialty information.

Dr. Pernick started the website in August 2001 by writing the Thyroid chapter in Microsoft Word while at a family camp, using his residency and fellowship notes, textbooks and other references. The underlying idea was that pathologists anywhere should be able to find the information they need, fast and free, and not rely on print references which may be outdated, in another location or available only for a fee.

Today, in our 20th year, our textbook of 5000 topics is maintained by 17 employees, our Editorial Board (Fig. 1) and 300+ active authors. The Editor-in-Chief (Dr. Debra Zynger) and Deputy Editors determine the textbook content, which focuses on entities likely to be encountered by practicing anatomic and clinical pathologists. Authors are staff pathologists who have published at least five non-case report journal articles about their subspecialty in the past 15 years and meet our other qualifications. Authors are assigned topics based on their publication history, using templates and guidelines similar to those in journals. All topics go through a peer review process.

In contrast to books and journals, topics on PathologyOutlines. com use bullets and are updated regularly. Sections include essential features of the topic, abundant high quality photomicrographs complete with captions and legends contributed by authors, a sample pathology report, detailed differential diagnoses and board review style questions. A recently written topic is Ovarian serous borderline tumor by Drs. Sharma and Lastra [1].

Received: March 7, 2021 Accepted: March 8, 2021

Corresponding Author: Nat Pernick, MD

PathologyOutlines.com, Inc., 30100 Telegraph Road, Suite 408, Bingham Farms, Ml 48025, USA

Tel: +1-248-646-0325, E-mail: Nat@PathologyOutlines.com

https://orcid.org/0000-0002-7020-7803
We also provide:

- Case of the Month with diagnostic microscopic images and a short but useful discussion; cases are also compiled by subspecialty.

- Books for pathologists with recommendations and various search criteria

- Jobs and Conference listings for pathologists with dynamic graphs. We recently published a summary of job trends in the US job market [2].

- A compilation of over 1600 Board review style questions, sorted by subspecialty.

- Libraries of educational information from advertisers, available 24/7/365, as well as Banners and E-blasts for information useful to pathologists.

Dr. Pernick, the founder and owner, is an AP/CP pathologist who has worked with computers since 1970, practiced law for 20 years and has owned many businesses. His philosophy is an important part of the business:

- The website should be fast, free and easy to use.

- The needs of pathologists are our top priority.

- We aim for exceptional treatment of employees, visitors and advertisers.

- We make charitable contributions a major part of our business. Currently, we sponsor a pandemic music relief program (https://www.pathologyoutlines.com/musicaward.html).

- We are always open to ideas on how to make the website more useful to pathologists. We also welcome ideas on how to use the worldwide network of pathologists connected through PathologyOutlines.com to help our profession and humanity. 


\section{References}

1. Sharma A, Lastra RR. Serous borderline tumor. PathologyOutlines. com website. https://www.pathologyoutlines.com/topic/ovarytumorserousborderline.html. Accessed March 8th, 2021.
2. Zynger DL, Pernick N. Understanding the Pathology Job Market: An Analysis of 2330 Pathology Job Advertisements From 2013 Through 2017. Arch Pathol Lab Med 2019;143:9-10.

\section{d. PathologyOutlines.com Editorial Board find pathology information fast}

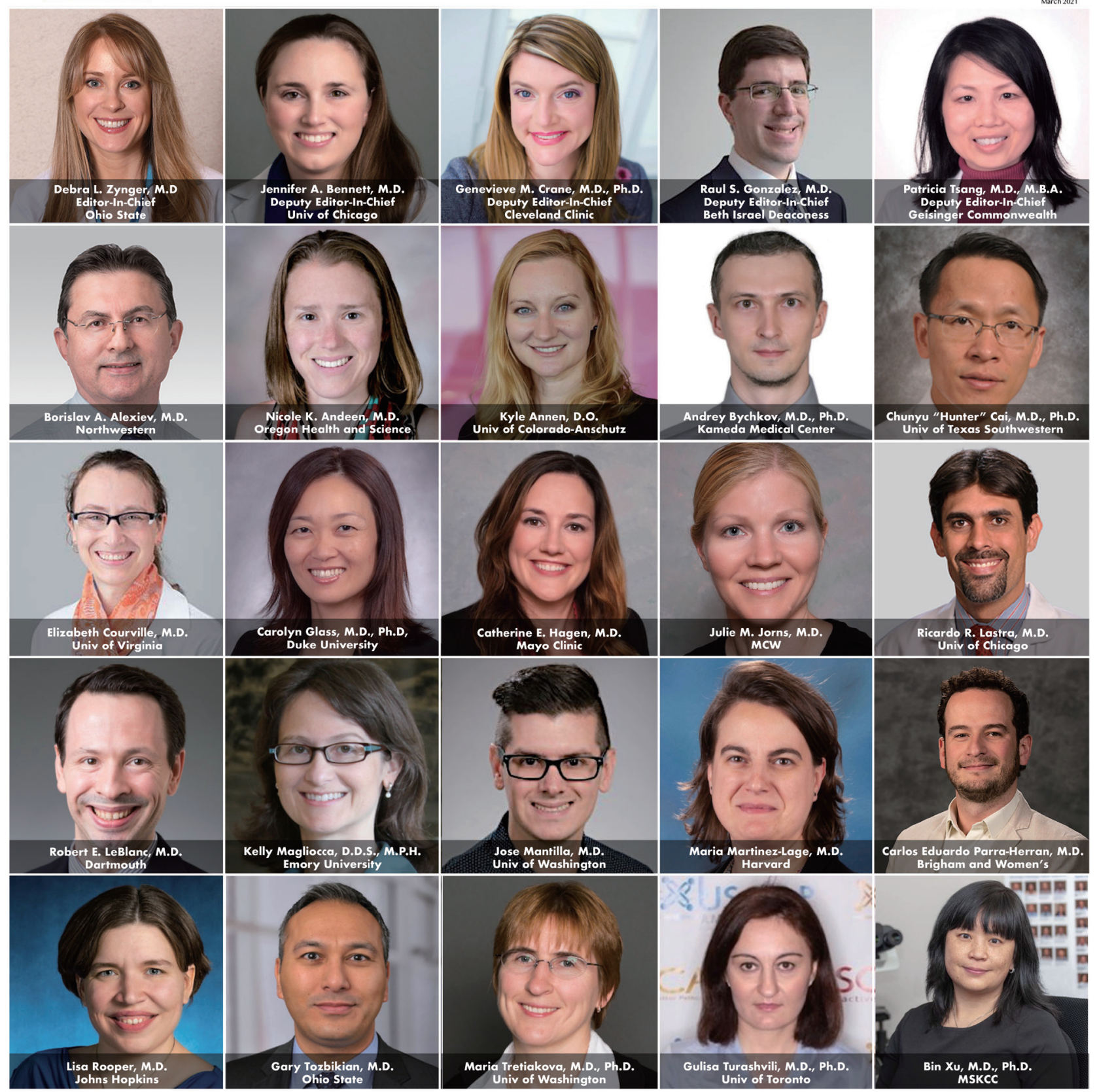

Fig. 1. Editorial Board of PathologyOutlines.com (March 2021). 